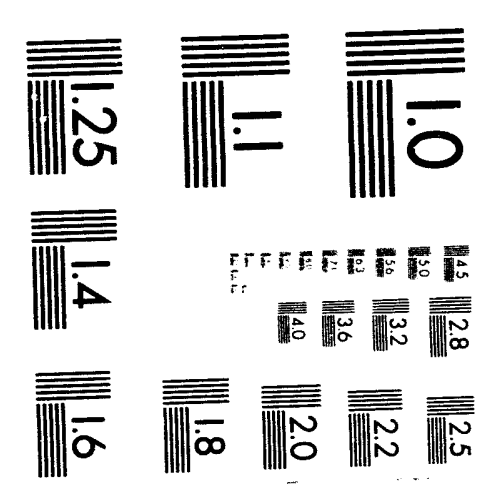



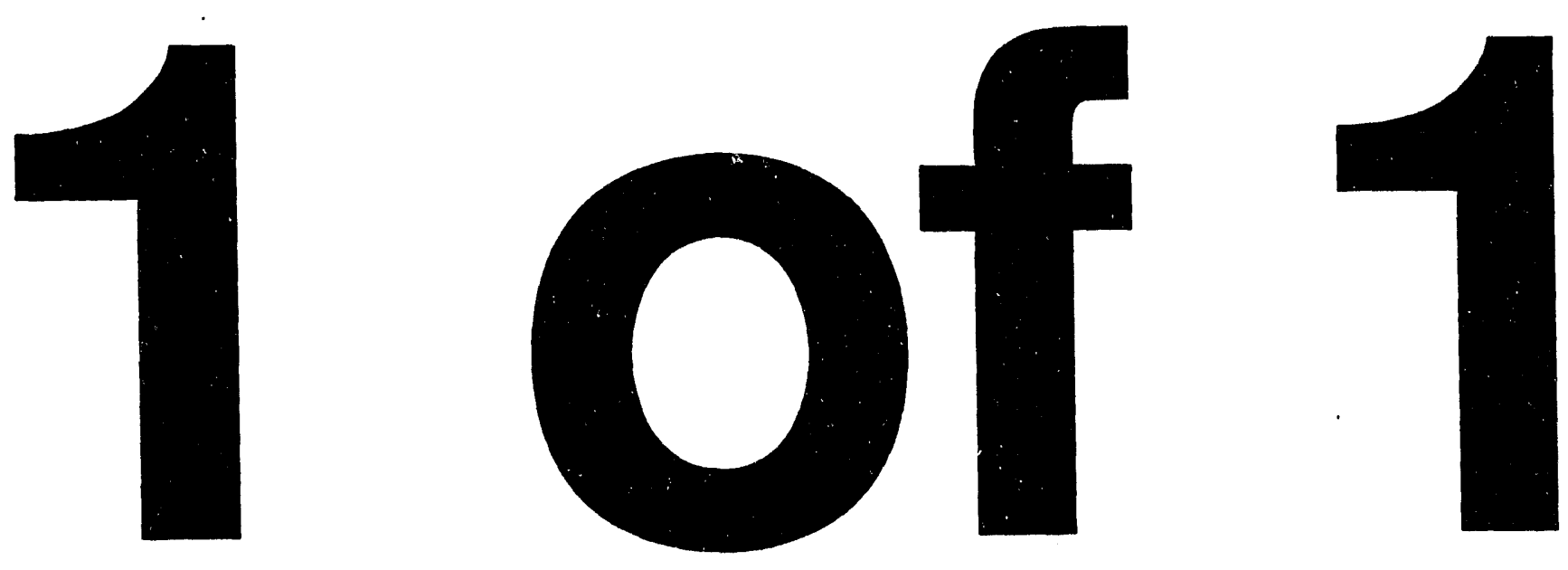


\title{
Assesment of Hoist Failure Rate for Payload Transporter III
}

\author{
Paul N. Demmie \\ Assessment Technology Department 12333 \\ Sandia National Laboratories \\ Albuquerque, NM 87185-0491
}

\begin{abstract}
Assessment of the hoist failure rate for the Payload Transporter Type III (PT-III) hoist was completed as one of the ground transportation tasks for the Minuteman III (MMII) Weapon System Safety Assessment. The failures of concern are failures that lead to dropping a reentry system (RS) during hoist operations in a silo or the assembly, storage, and inspection building for a MMIII wing. After providing a brief description of the PT-III hoist system, we summarize our search for historical data from industry and the military services for failures of electric hoist systems. Since such information was not found, our strategy for assessing a failure rate was to consider failure mechanisms which lead to load-drop accidents, estimate their rates, and sum the rates for the PT-III hoist failure rate. We discuss failure mechanisms and describe our assessment of a chain failure rate that is based on data from destructive testing of a chain of the type used for the PT-III hoist and projected usage rates for hoist operations involving the RS. Our main result provides upper bounds for chain failure rates that are based on these data. No test data were found to estimate failure rates due to mechanisms other than chain failure. We did not attempt to quantify the effects of human factors on the PT-III hoist failure rate.
\end{abstract}

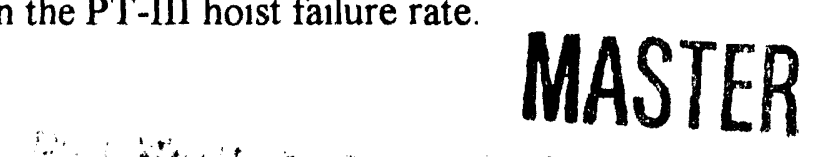


This Page Intentionally Left Blank 


\section{Table of Contents}

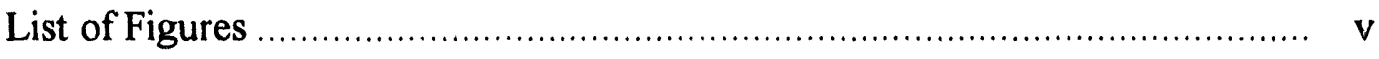

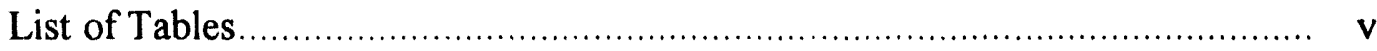

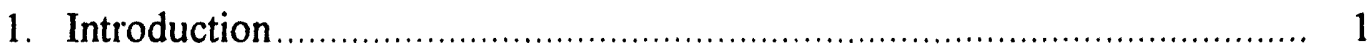

2. The PT-III Hoist System ........................................................... 3

3. Summary of Search for Information ................................................. 5

4. Failure Mechanisms for Load-Drop Accidents ............................... 11

5. Failure Rate for Chain ............................................................. 13

6. Discussion of Other Failure Mechanisms .......................................... 17

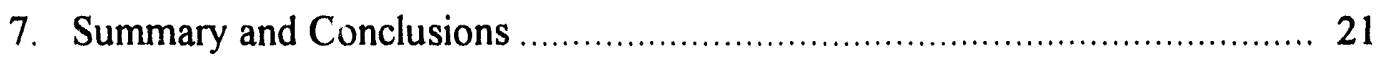

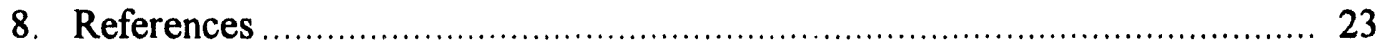


This Page Intentionally Left Blank 


\section{List of Figures}

Figure 1. Schematic of the PT-III Hoist System ...................................... 3

Figure 2. Articulation of chain through the PT-III Hoist System ................ 4

Figure 3. Fault tree for a load drop during PT-III hoist operations .............. 11

\section{List of Tables}

Table 1. PT-III Hoist Usage Rates per Wing ........................................ 8

Table 2. Loadings of RS per Year at a MMIII Wing ........................... 8

Table 3. Weights of Aerospace Vehicle Equipment ........................... 9

Table 4. Failure Loads for PT-III Hoist Chain ..................................... 13 
This Page Intentionally Left Blank 


\section{Introduction}

Assessment of the failure rate for the Payload Transporter Type III (PT-III) Hoist was completed as one of the ground transportation tasks for the Minuteman III (MMIII) Weapon System Safety Assessment (WSSA). The task is

\section{Task 5: Assessment of PT Hoist Failure Rate.}

The PT-III hoist failure rate will be assessed using historical data from industry and the military services for hoists of comparable design and usage (load weights, frequency of usage, etc.).

While failure of a system, subsystem, or component is generally defined as an inability to perform its intended function, failure in the present effort is considered any event which results in dropping the reentry system (RS) during hoist operations at a MMIII wing. Such failures are a concern since dropping a RS is an initiating event that could lead to plutonium dispersal or nuclear detonation. Hoist failure rate is one input for the event trees used to quantify the risk associated with MMIII operations.

Our study concludes that the PT-III hoist is well-designed and incorporates large safety factors. Based on test data from Martin Marietta Corporation, we determined an upper bound of $4 \times 10^{-14} \mathrm{RS}$ drops per year due to chain failure for $718 \mathrm{RS}$ mate or demate operations per year at the silos of a MMIII wing and an upper bound of $1 \times 10^{-14} \mathrm{RS}$ drops per year due to chain failure for $260 \mathrm{RS}$ upload or download operations per year at the assembly, surveillance, and inspection (AS\&I) building. On the basis of Duff-Norton Company fatigue test data for the hoist chain, we do not expect the chain to fail due to fatigue. No data were found to estimate failure rates due to mechanisms other than chain failure. However, other failure mechanisms are not expected to result in upper bounds larger than those for chain failure. In our opinion, human error will contribute more to load-drop accidents than mechanical failures in the hoist system. Of particular concern is an operator failing to detect flaws in the chain. We did not attempt to quantify the effects of human factors since this task was beyond the scope of our study.

We discuss the assessment of the PT-III hoist failure rate in the following sections of this report:

2. The PT-III Hoist System

3. Summary of Search for Information

4. Failure Mechanisms for Load-Drop Accidents

5. Failure Rate for PT-III Hoist Chain

6. Discussion of Other Failure Mechanisms

7. Summary and Conclusions

8. References 
This Page Intentionally Left Blank 


\section{The PT-III Hoist System}

The PT-III hoist is used in MMIII silo operations to attach or remove the reentry system (RS), the missile guidance system (MGS), and propulsion system rocket engine (PSRE) from the lower stages of the MMIII missile. Since the RS is attached above the MGS which is attached above the PSFE, the RS must be removed whenever the MGS or PSRE needs replacing. The MGS and PSRE are often moved as a unit and are referred to as the post-boost control system (PBC,S).

The PT-III Hoist System consists of an electric hoist unit, a load chain, bridges, trolley, motors, brakes, and a load block with a clevis or hook attached. Figure 1 is a diagram of the PT-III Hoist System. Figure 2 shows the articulation of the chain through the system with one end free, the chains path through the hoist unit and over five idler sprockets, and the other end of the chain attached to the bridge. The hoist system is mounted on rails which extend the full length of the PT-III and are fastened to its vertical ribs. The system is rated at 3,000 pounds. All structural components including the PT-III van structure are designed with a safety factor of 3 , the chain and hook with a safety factor of 5 , and the load block with a safety factor of 10 .

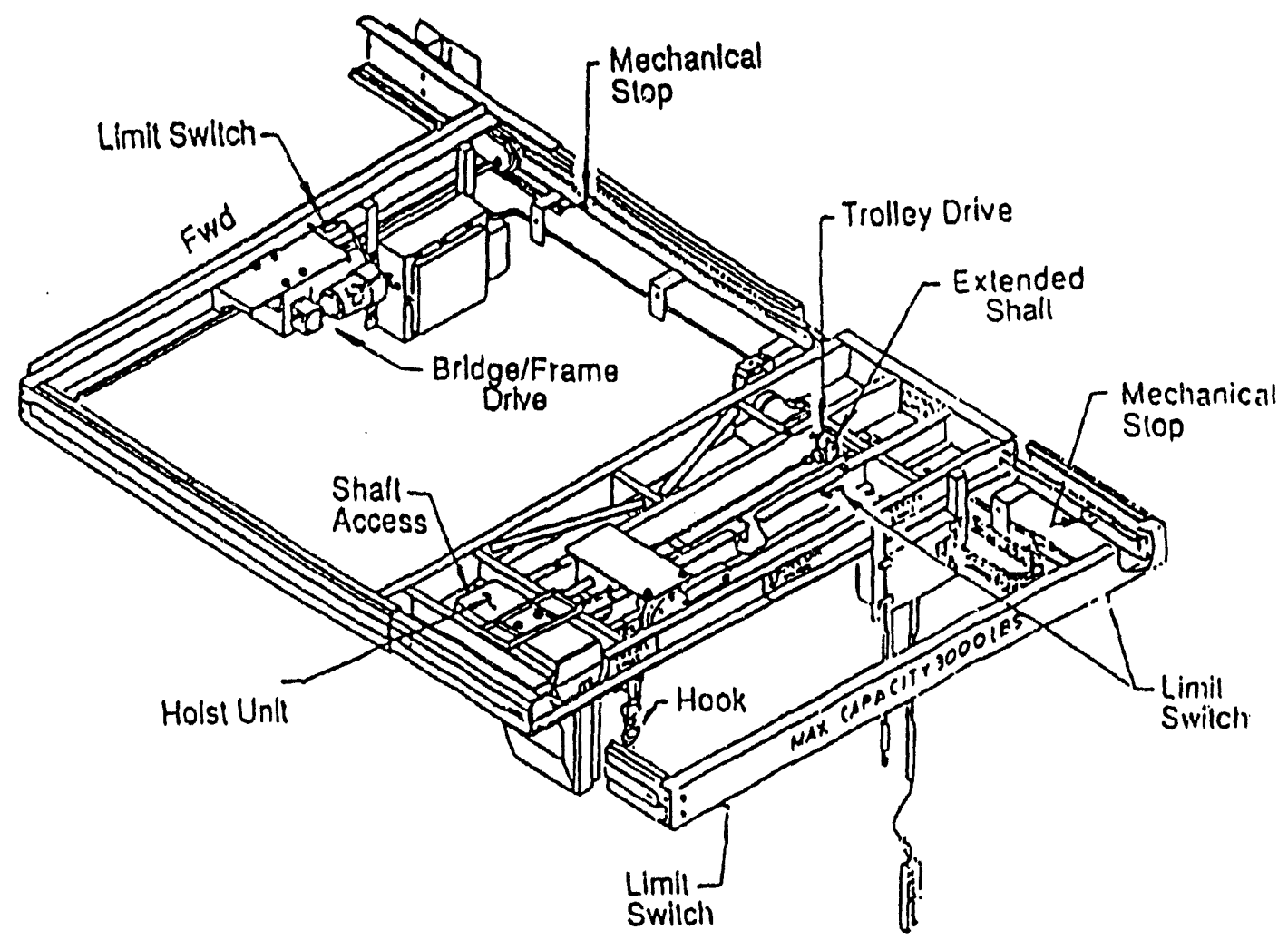

Figure 1. Schematic of the PT-III Hoist System. 


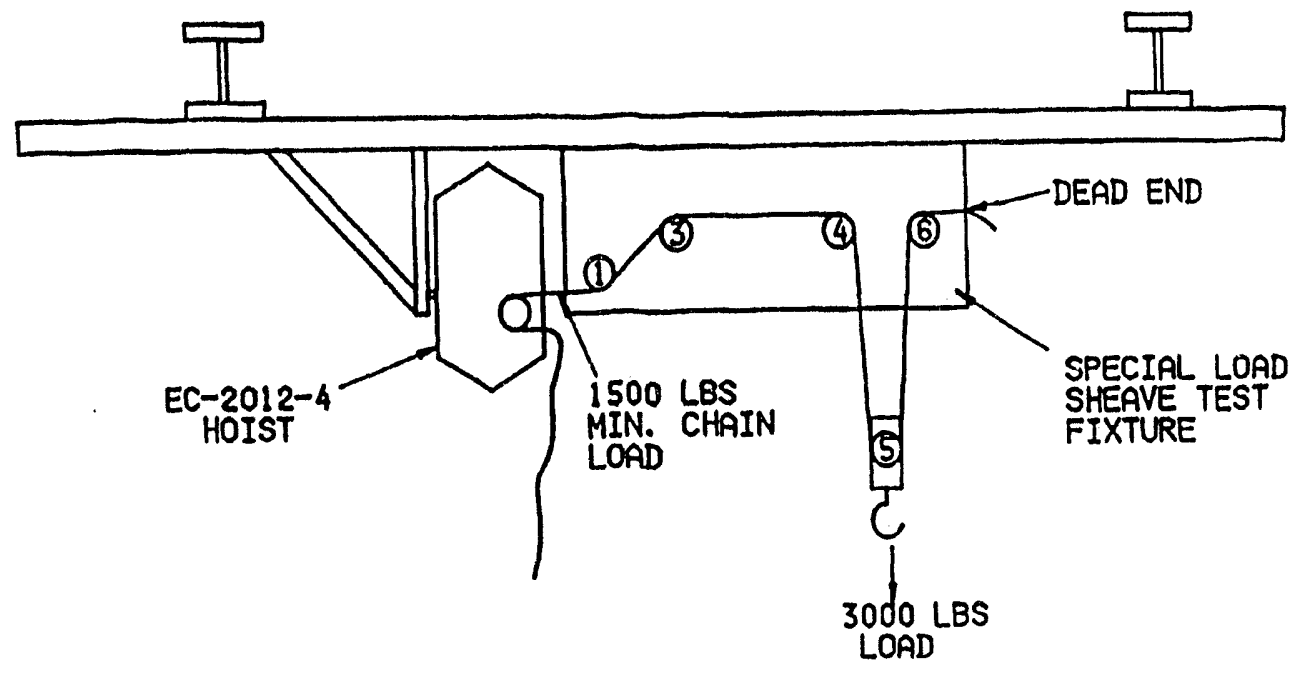

Figure 2. Articulation of chain through the PT-III Hoist System.

The hoist unit is an EC-2012-4 unit produced by the Duff-Norton Company. Duff-Norton states that the EC-2012-4 design is standard with slight changes to the hook and the electric motor. The hook has a higher capacity than is normal for their 3,000-pound electric hoists. To meet the safety factor of 5 for a 3,000 pound load, DuffNorton provided a 3-ton rated hook for the PT-III hoist. It is a forged Crosby Hook made of 1035 carbon steel. Although a hook is provided with the hoist system, we observed that no hook was used with the hoist on the Payload Transporter Type II (PT-II) during PT-II operation at Vandenberg Air Force Base. A hook was only used with a different hoist during opeartions in the AS\&I building. The gear box is designed for a 1-hp motor, although the PT-III hoist uses a $3 / 4$ hp motor to limit the lifting speed to 6 feet per minute. The brakes on the hoist are a mechanical Weston brake that requires a positive action to release and an electric brake on the motor shaft that requires power to a solenoid to release. Upon losing electrical power, either brake will stop vertical movement of the hoist automatically within 1.0 inch with loads up to 3,000 pounds. Both brakes acting together are capable of holding a minimum of 3,750 pounds. Electric limit switches are provided to terminate power for any single direction at the limit of travel. 


\section{Summary of Search for Information}

Our assessment began by searching for historical data from industry and the military services for failures of electric hoist systems of comparable design and usage. In this section we summarize our activities to acquire information on hoist failures.

We formally requested the following information on July 15, 1992

1. Documentation, data, and any other information concerning past failures of the hoist assembly for the PT-II van

2. Design definition of the hoist assemblies for the PT-II and PT-III vans.

3. Reliability predictions and documentation from any reliability testing on the hoist assemblies for the PT-II and PT-III vans.

4. Manufacturers of hoist assemblies for the PT-II and PT-III vans.

5. Load weights for items moved using the hoists.

6. Frequency of usage of the hoists

7. Other industrial uses and for this type of hoist and any known users of this type of hoist.

We requested the PT-II hoist information to assess its applicability to the PT-III hoist failure rates. Mr. Perry D'Antonio included these requests in a letter to Capt. Bredehoft at the Defense Nuclear Agency (DNA).

Mr. Gil Garcia at Philips Lab provided information about Items 1, 3, 4, 5, and 6 in addition to a copy of Reference 1, ICBM Replacement Warhead Phase I Study Safety Working Group Report by Homsy, Basinger, and Moor at Lawrence Livermore National Laboratory (LLNL).

Reference 1 includes an estimate of a failure rate for the PT-III hoist system based on the hook failure rate found in Reference 2, OREDA Offshore Reliability Data Handbook. We obtained Reference 2 and will discuss the applicability of the hook failure rate in Section 6 of this report.

Mr. Garcia also provided a copy of Reference 3, the Martin Marietta Corporation report MCR-92-6523, Payload Transporter Type III Qualification Test Report Qualification Load and Functional Test. Reference 3 contains data from five destructive tests that determine loads sufficient to break the type of chain used for the PT-III hoist. In Section 5 we use these data, the load weights, and the projected frequency of hoist usage to determine an upper bound for the failure rate due to the chain breaking during PT-III hoist operations.

We requested Ms. Gladys Sheldon at the Sandia National Laboratories (SNL) Technical Library to perform a literature search for documents relating to hoists and hoist failures. She searched for documents from the following sources: 
1. DIALOG - Compendex

2. Defense Technical Information Center (DTIC)

3. NASA/Recon

4. SNL Reports Catalog

We requested several documents from this search, but found no information on hoist failures in them. Some documents on failure of cables and on failures of a reeving hoist using wire cable were requested since the RS is supported by cables rather than the hoist for part of mate or demate operations in a silo.

A useful report is Reference 4, Orbiter Processing Facility Service Platform Failure and Redesign by Jesse L. Harris of Lockheed Space Operations Company, which is listed in the NASA/Recon search and found in the SNL Technical Library. The platform is used to service the space shuttle at the Kennedy Space Center. Reference 4 discusses an accident in which the hoist system failed and caused the platform to fall. We will discuss this accident in Section 6.

In Reference 5, Encyclopedia of Associations, the address and phone number of the Hoist Manufacturing Institute (HMI) was found. We spoke with Mir. Claude Carraux at HMI. $\mathrm{He}$ and his associates do not know of any compilation of hoist failures. He provided the name and phone number of an engineer at the Duff-Norton Company which produced the PT-III hoist unit.

We called Duff-Norton Company and spoke with Mr. Ron Foltz who is a product development engineer. He knows of no compilation of failures of their equipment. He provided some of the design information presented in Section 2. He felt that failures are dominated by chain breaks because of chain fatigue and the articulation of the chain over the idler sprockets. He sent me a copy of Reference 6 that gives the relationship between load weight and the mean cycles between failures (MCBF) in an exponential failure model. This relationship is called the S-N curve for the chain and is based on test data. We will discuss this information in Section 5.

Mr. Homsy at LLNL contracted EG\&G to perform a literature search on hoist failures. We contacted Mr. Artie Debeling who is the engineer at EG\&G responsible for this work. $\mathrm{He}$ indicated that he found the hook failure rate cited in Reference 1 and documented some concerns about its applicability. He found no other failure information. However, he feels from his study of the system using the limited drawings available that a possible failure mode would be breaking the weld in the clevis or parts of the sling or handling fixture. Mr. Debeling agreed that chain breaking may occur in a situation where the upper limiter switch failed and the motor continues to pull on the chain. Failure data for welds are found in Reference 7, Nonelectronic Parts Reliability Data 1991. We obtained a copy of this document. Although Reference 7 has no data on failures of hoists, it could be useful as a source of surrogate data for fault-tree analyses of a hoist system. 
On November 20, 1992, we received the following Martin Marietta documents from R\&D Associates (RDA) in response to our request to Capt. Bredehoft:

Control Number

MCR-90-3201

MCR-90-3221

MCR-90-3222A

MCR-90-3223-02

MCR-90-3229-01

MCR-90-3230

MCR-92-6523

MCR-92-6533
Brief Title

Reliability Program Plan, PT III

Static Stress Analysis

Semitrailer, PT, Operating and Support

Hazard Analysis Report

Semitrailer, PT, Nuclear Safety Analysis

Report

Failure Modes, Effects, \& Criticality

Analysis

Reliability Predictions Report

PT, Type III, Quantification Load and

Functional

PT, Type III Reliability Test

Reference 8, MCR-90-3223-02, lists the destructive testing data for chain failure and loadblock failure. Reference 9, MCR-90-3230, lists a failure rate for the chain that is neither supported nor consistent with the Duff-Norton data for failure due to chain fatigue. We will discuss chain and load-block failure rates in Sections 5 and 6, respectively.

We contacted Mr. Robert Shanks at TRW Ogden to discuss hoist usage rates per wing. He confirmed the usage rates provided by Mr. Garcia. These usage rates are listed in Table 1. Table 1 indicates that there are expected to be 1,240 hoist cycles per year at each wing and 206.67 cycles per year for each of the six PT-III vans if they are utilized equally. Uploading and downloading aerospace vehicle equipment constitutes one cycle. Mr. Shanks stated that the cycles given in Table 1 are hoist movements with RS, PBCS, or MGS on hoist at the silo or AS\&I building. The usage rates given in Table 1 are based on projected future operations and differ from the usage rates presented in Reference 1 that were based on past operations. 


\begin{tabular}{|c|c|c|c|}
\hline \multicolumn{4}{|c|}{ Table 1. PT-III Hoist Usage Rates per Wing } \\
\hline Task & $\begin{array}{c}\text { Number of } \\
\text { Dispatches }\end{array}$ & $\begin{array}{c}\text { Numberof Hoist } \\
\text { Cycles per Year }\end{array}$ & $\begin{array}{c}\text { Numberof Hoist } \\
\text { Cycles per } \\
\text { PT-III }\end{array}$ \\
\hline One-Way w/RS & 109 & $218(2)$ & 36.33 \\
\hline One-Way w/PBCS & 109 & $218(2)$ & 36.33 \\
\hline Round Trip w/RS (LLCs) & 21 & $84(4)$ & 14.00 \\
\hline Round Trip w/MGS & 120 & $720(6)$ & 120.00 \\
\hline Total & 359 & 1,240 & 206.67 \\
\hline
\end{tabular}

RS is Reentry System, PSRE is Propulsion System Rocket Engine, LLCs is Limited Life Component Exchanges, MGS is Missile Guidance System, and PBCS is post-boost control system consisting of the PSRE and MGS. The number in parentheses represents hoist cycles loaded with aerospace vehicle equipment per dispatch. There are six PT-III vans deployed per wing.

However, only 718 loadings (up or down) of the 1,240 hoist cycles involve movement of the RS at the silos for a MMIII wing and 260 loadings involve movement of the RS at the AS\&I building. Table 2 summarizes the loadings of a RS per year at a MMIII wing.

Table 2. Loadings of RS per Year at a MMIII Wing

\begin{tabular}{|c|c|c|c|}
\hline Task & $\begin{array}{c}\text { Number of } \\
\text { PT-III } \\
\text { Dispatches }\end{array}$ & $\begin{array}{c}\text { Number of } \\
\text { RS Loadings } \\
\text { in Silos }\end{array}$ & $\begin{array}{c}\text { Number of } \\
\text { RS Loadings } \\
\text { in AS\&I }\end{array}$ \\
\hline One-Way w/RS & 109 & $218(2)$ & $218(2)$ \\
\hline One-Way w/PBC & 109 & $218(2)$ & \\
\hline Round Trip w/RS (LLCs) & 21 & $42(2)$ & $42(2)$ \\
\hline Round Trip w/MGS & 120 & $240(2)$ & \\
\hline Total & 359 & 718 & 260 \\
\hline
\end{tabular}

RS is Reentry System, PSRE is Propulsion System Rocket Engine, LLCs is Limited Life Component Exchanges, MGS is Missile Guidance System and PBCS is post-boost control system consisting of the PSRE and MGS. The number in parentheses is number of RS loadings per dispatch. There are six PT-III vans deployed per wing. 
Further discussion with Mr. Shanks provided the weights of the RS including sling, PSRE, MGS, and PBCS. Table 3 lists the unclassified weights of these components provided by Mr. Shanks.

\begin{tabular}{|c|c|}
\hline \multicolumn{2}{|c|}{$\begin{array}{c}\text { Table 3. Weights of Aerospace Vehicle } \\
\text { Equipment }\end{array}$} \\
\hline Component & Weight (pounds) \\
\hline RS and Sling & 2,750 \\
\hline MGS & 340 \\
\hline PSRE & 650 \\
\hline PBCS & 990 \\
\hline
\end{tabular}

RS is Reentry System, PSRE is Propulsion System Rocket Engine, LLCs is Limited Life Component Exchanges, MGS is Missile Guidance System and PBCS is post-boost control system consisting of the PSRE and MGS.

The actual weights of these components are classified and would be of no analytical significance. Mr. Shanks also provided some component specifications that are pertinent to an accident scenario similar to the service platform accident at the space shuttle Orbiter Processing Facility. 
This Page Intentionally Left Blank 


\section{Failure Mechanisms for Load-Drop Accidents}

Our information search did not find data for failure of hoist systems similar to the PT-III hoist system. Therefore, our strategy for assessing a hoist failure rate was to estimate failure rates for failure mechanisms and combine them for the total hoist failure rate.

Figure 3 is a fault tree for the undesired event (top event) of "Reentry System Drop Occurs during Hoist Operations."

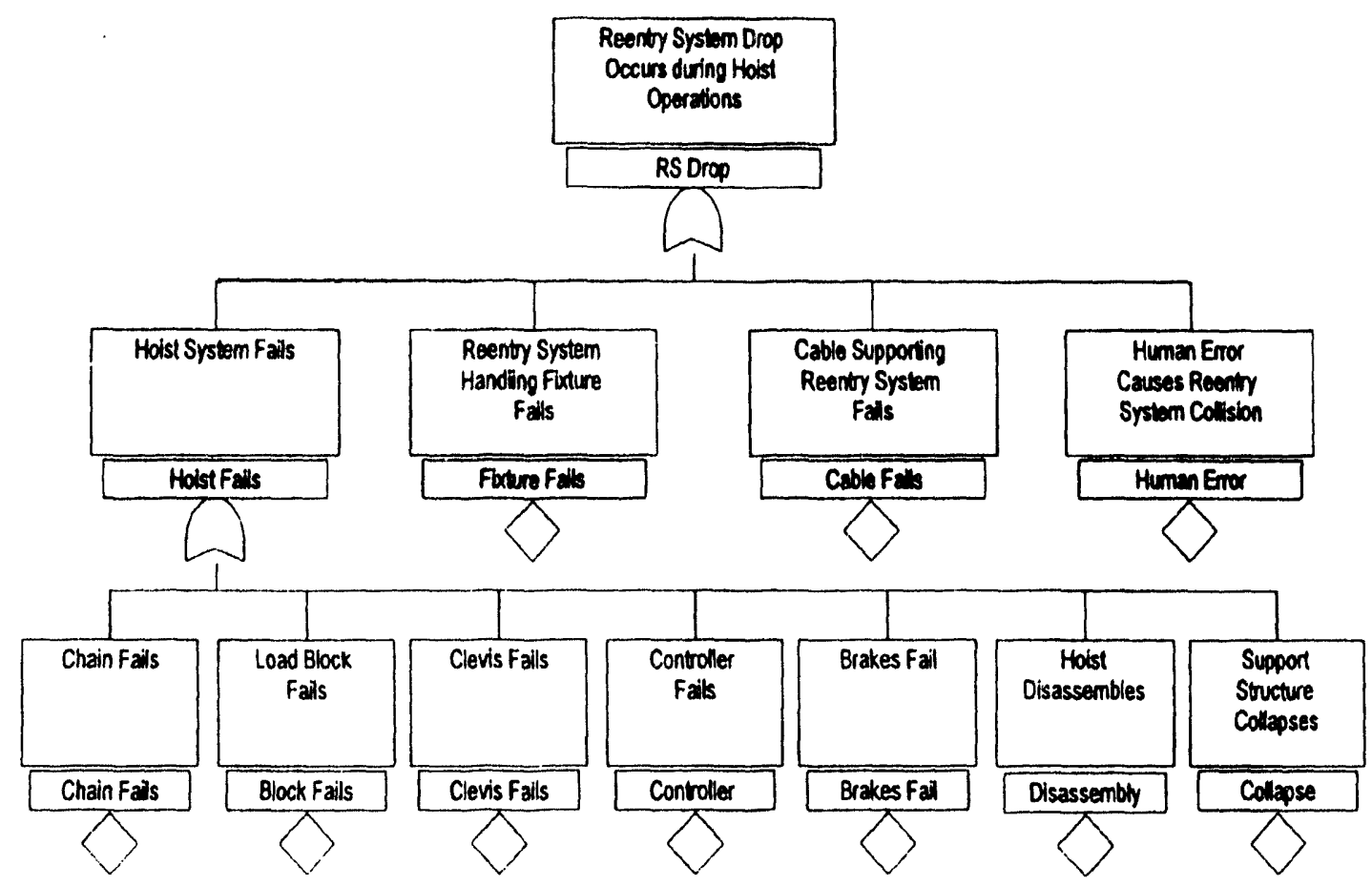

Figure 3. Fault tree for a load drop during PT-III hoist operations.

The first level of development for this fault tree contains the nodes "Hoist System Fails," "Reentry System Handling Fixture Fails," "Cable Supporting Reentry System Fails," and "Human Error Causes Reentry System Collision."

From sketches and information on the PT-III hoist and the basic design of an electric chain hoist, the following mechanical failure mechanisms apply to the PT-III hoist system and are shown in the development of the node "Hoist System Fails:"

1. Chain Failure

2. Load Block Failure

3. Clevis Failure 

4. Controller Failure
5. Brake Failure
6. Hoist Disassembly
7. Support Structure Collapse

References 3,6 , and 8 contain information to estimate rates for chain failure due to loading and chain fatigue. These rates are discussed in Section 5. Reference 8 contains one data point for PT-III load-block failure. No data was found which could be used to obtain failure rates due to the other mechanisms. Failures due to load-block failure or other mechanisms are discussed in Section 6. Failure rates for mechanisms other than chain failure will most likely require further destructive testing or fault-tree analyses using surrogate data.

Controller and brake failure are included at this level of development even though their failure can cause a load-drop accident where the RS remains attached to the hoist system. Non-freewheeling accidents during which the RS remains attached to the hoist are a concern only if the RS colliding with the MGS or AS\&I building floor at 6 feet per minute could lead to plutonium dispersal or nuclear detonation. We have no estimates of the consequences of such collisions involving the RS.

We did not assess failures of the RS handling fixture or the cable support structure since DNA tasked these activities to Waterways Experiment Station. The RS is suspended for a short time from four floor-hatch lugs using cables between the lugs and the RS handling fixture while the nose cone is mated to the RS. Although the RS handling fixture and the cable support system are not part of the hoist system, we will comment on their probabilities of failure in Section 6

"Human Error Causes Rentry System Collision" is included at the first level since a loaddrop accident occurs if an operator neglects to stop hoist movement before the RS collides with the MGS or AS\&I building floor at 6 feet per minute. Other human factors would contribute to further developments of the fault tree. We will discuss human error in Section 6 


\section{Failure Rate for Chain}

Three sources of information were found to assess the failure rate for the chain: data from destructive testing of the chain to failure, the SN curve from Duff-Norton tests, and a failure rate from Reference 9.

Selected samiles of the chain were tested to loads above 7,500 pounds until failure occurred. Table 4 lists the five loads at which failure occurred.

\begin{tabular}{|c|}
\hline Table 4. Failure Loads for PT-III Hoist Chain \\
\hline Weight of Failure Load (pounds) \\
\hline 13,900 \\
\hline 14,500 \\
\hline 14,800 \\
\hline 13,900 \\
\hline 15,400 \\
\hline Average 14,500 \\
\hline
\end{tabular}

We use this data as follows to determine a failure rate for the chain due to loading. The data in Table 2 is used to estimate the parameters $\alpha$ and $\beta$ for the log-normal distribution

$$
\frac{1}{\sqrt{2 \pi} \beta \mathrm{x}} \mathrm{e}^{-(\ln \mathrm{x}-\alpha)^{2} / 2 \beta^{2}} \text {, }
$$

where $x$ is the value of the random variable. The parameters $\alpha$ and $\beta$ are the mean and standard deviation of the natural logarithms of the failure loads in Table 4, 9.581 and 0.0436 , respectively.

Since the tension on the double-reeved chain with a load of 3,000 pounds is 1,500 pounds, the probability that the chain will fail with a hoist load less than or equal to 3,000 pounds is

$$
\int_{0}^{500} \frac{1}{\sqrt{2 \pi \beta x}} \mathrm{e}^{-(\ln \mathrm{x}-\alpha)^{2} / 2 \beta^{2}} \mathrm{dx} .
$$


Since the ranges of available normal probability tab! ss are not sufficient to evaluate this integral, we used Microsoft Excel to evaluate the cumulative log-normal distribution at 1,500. However, Excel obtained zero for the probability. Use of the inverse to the cumulative log-normal distribution in Excel showed that the largest nonzero probability that corresponds to a nonzero load is $1 \times 10^{-7}$. Therefore, we wrote a computer program in Microsoft FORTRAN to calculate cumulative normal or log-normal distributions. This program was based on the numerical software for the error function included in the diskette provided with Reference 10, Numerical Methods and Software by Kahaner, Moler, and Nash. Our program calculated a value of zero for an argument of 1,500. Further investigation showed that the smallest nonzero probability that can be computed by our code is $6 \times 10^{-17}$. This probability, $p$, corresponds to a load on the chain of 10,055 pounds.

If an event occurs with a probability $\mathrm{p}$ in one trial, the probability that the event will first occur on trial $\mathrm{x}$ is given by the geometric distribution (Reference 11),

$$
g(x)=p(1-p)^{x-1} \quad x=1,2,3, \ldots
$$

The cumulative geometric distribution is

$$
G(x)=\sum_{i=1}^{X} g(i)=1-(1-p)^{x}
$$

The probability of an RS drop during a year with 718 mate or demate operations in a silo is $\mathrm{G}(718)$. The probability of an RS drop during a year with 260 upload or download operations in the AS\&I building is $G(260)$. Therefore, failure load test data implies an upper bound of $4 \times 10^{-14} \mathrm{RS}$ drops per year at the silos for a MMIII wing performing 718 RS mate or demate operations in a year and an upper bound of $1 \times 10^{-14} \mathrm{RS}$ drops per year at the AS\&I building for a wing performing 260 RS upload or download operations in a year.

Reference 6 is a test report for fatigue testing of the JL-19-1B chain used in the PT-III hoist system. The fatigue tests were performed to determine an endurance limit to compare with pre-production lots of the chain.

The fatigue tests were performed using the Vishay fatigue tester. A fatigue load cell, Vishay bridge amplifier, and Tektronix oscilloscope were used to measure the loads. The tests were performed with an initial load of 5,000 pounds and were decreased in 500 -pound increments to 3,000 pounds. Five samples of the $9 / 32$-inch diameter chain were tested at each load

An S-N curve was plotted using the fatigue data. This curve relates the load (ordinate) with the cycles to failure (abscissa). The horizontal asymptote is the endurance limit. $\mathrm{Mr}$. 
Foltz stated that this limit is usually reached at approximately $10^{8}$ cycles. The data from the Duff-Norton tests imply an endurance limit of 3,300 pounds.

Figure 2 shows the double reeving of the chain. Therefore, the tension in the chain for a 3,000-pound load is 1,500 pounds. Therefore, we conclude from the fatigue tests and the load weights listed in Table 4 that test data for chain fatigue implies an endurance limit of 3,300 pounds. This limit and the load weights imply that the chain is not expected to fail due to fatigue during hoist operations involving an RS, MSG, or PSRE.

Reference 9 lists a chain failure rate of $1.00 \times 10^{-7}$ per hour, but provides no justification for this value other than referring to Peacekeeper Transportation and Handling as the data source. Although we do not recommend using this rate, consider the implication of interpreting it as the failure rate in an exponential distribution of failure times. A failure rate of $\lambda$ equal to $1.00 \times 10^{-7}$ per hour corresponds to a MCBF of about $5.6 \times 10^{7}$ for a load traveling 18 feet at 6 feet per minute. If the failure rate is attributed to chain fatigue, the Duff-Norton S-N curve implies that this MCBF corresponds to a load of approximately 3,400 pounds. The cumulative probability distribution for an exponential density with parameter $\lambda$ is from Reference 11

$$
F(t)=1-\exp (-\lambda t)=1-\exp (- \text { CYCLES / MCBF }))
$$

where CYCLES is the number of cycles during time interval from 0 to time $t$. The failure rate listed in Reference 9 implies $1.8 \times 10^{-5}$ RS drops per year in hoist operations for a wing using six PT-III vans, each operating for 120 mate or demate operations. 
This Page Intentionally Left Blank 


\section{Discussion of Other Failure Mechanisms}

In this section we will discuss failure mechanisms other than chain failure that can cause a load-drop accident during PT-IIl operations involving its hoist. The discussion includes the hook failure rate cited in Reference 1, the single data point for destructive failure of the load block and its implications, and our perception of the role of human factors in load-drop accidents. A prelude to the human factor discussion will be a summary of an accident that occurred at the Kennedy Space Center.

Reference 2 provides a failure rate for a hook. The published rate was obtained from reliability data for offshore oil well drilling equipment used in North Sea platform drilling operations. Since the handbook was published in 1984, no data past 1984 contributes to the published value. No information on the design or rating of the hooks used in these drilling operations is found in Reference 2. The hook sketched in this reference does not look like a standard hook. Furthermore, the PT-III hoist uses a clevis on the load block to attach the RS handling fixture to the hoist. During our observations of PT-II van operations, a hook was used only with a hoist in the AS\&I building and not with the hoist in the PT-II van.

Reference 2 states that there was one structural failure (rupture) of the hook in 370,700 demands. It lists a mean failure rate for an exponential time-to-failure density of $7.5 \times 10^{-6}$ per hour (calendar time) and a $90 \%$ confidence interval of $3.9 \times 10^{-7}$ per hour to $3.6 \times 10^{-5}$ per hour. It is significant that the aggregated time in service used to calculate this rate is calendar time and not operational time. Use of operational time is essential for its application to PT-III hoist failure: calendar time is only appropriate for applications to hooks of similar designs and environments. Also, we expect that the harsh environment accelerates failure of any equipment whose reliability is given in Reference 2 . We conclude that the hook failure rate published in Reference 2 is not applicable to PT-III hoist failure not only because a hook is not used with the PT-III hoist, but also because hooks used in offshore oil drilling operations may differ in design and rating, are exposed to a harsh ocean environment, and the stated failure rate is based on calendar time and not operational time.

Reference 8 states that the load block was destructively tested and failed with a load of 43,750 pounds. This failure load indicates ample margin of ultimate strength since the 10:I safety factor only requires a proof load of 30,000 pounds. Further destructive tests were not performed since destructive testing of the load block was not required. If the failure load of 43,750 pounds is near the average and the standard deviation of additional data would be on the order of the standard deviation for the chain failure data, we expect a failure probability no larger than the probability calculated for chain failure. Similarly, we would expect similar low probabilities for failures of all components that were designed with PT-III safety factors. 
As noted previously, the RS is suspended for a short "ime from four floor hatch lugs using cables between the lugs and the RS handling fixture. The lugs are designed to support a 9,000 pound load and are proof loaded with a 4,000 pound weight. For the same reasons that we expect low failure probabilities for components that were designed with PT-III safety factors, we expect a failure involving the lug and cable support system or the RS handling fixture to occur with a probability no larger than the probability for chain failure.

There are several methods to estimate failure rates for mechanisms other than chain failure. The most direct method is to destructively test all system components whose failure leads to a load-drop accident. Determining the critical components can be accomplished by further developing and analyzing a fault tree similar to the tree shown in Figure 3. Also, one could estimate failure rates by using surrogate data to quantitatively solve the fault tree for failure probabilities. While the method is appropriate, the availability, applicability, and quality of surrogate data are suspect.

Although large amounts of reliability data are available in references such as Reference 7 , the component descriptions are sparse and doubt exists concerning applicability of the published data. Furthermore, since reliability is the probability that a component will perform its intended function for a specified period of time under specified conditions, published reliability data may not be completely applicable to determine failure causing a particular accident. For example, reliability data for a hoist controller would include both the probability that the controller will start or stop movement of the hoist. However, only the failure of a controller to stop hoist movement would cause a load-drop accident and the collision of the RS with the MGS. On the other hand, the reliability data for the brakes would be completely applicable since their failure would cause a load-drop accident.

On March 8, 1985, in a high bay of the Orbiter Processing Facility (OPF) at the Kennedy Space Center, an accident occurred which resulted in a service platform falling and striking a technician. Reference 4 documents this accident. While this accident is not directly applicable to PT-III hoist failure, it does give insight into how load-drop accidents can occur.

The direct cause of the accident was a failure of a master link in the hoist system that allowed the service platform to fall. The platform reached its vertical movement limit but the hoist continued to drive upward because a misadjusted electrical limit switch failed to stop the platform's motion. Although a master link had previously failed and the piatform was tagged out, the mishap occurred upon failure of a second master link. The accident was attributed by investigators to operator error due to unauthorized use of the taggedout platform. Several design deficiencies that could have mitigated the accident and production quality issues were noted in the report. Thus, Reference 4 suggests that inadequate design of the hoist system, quality control in the production of components, and human error contributed to the OPF platform accident. 
The OPF platform accident suggests the possibility of an accident during PT-III operations where the controller and limit switches fail to stop upward movement and the hoist motor continues to apply force until the chain or load block breaks. However, a similar accident during PT-III operations is not expected since the transmission clutch slips for loads exceeding 4,000 pounds and the motor will burn out for loads exceeding 6,000 pounds.

The PT-III hoist system is well designed with large safety factors for its components. Therefore, we expect that load-drop accidents due to component failures are unlikely. However, as was illustrated by the OPF platform accident, the role of human error in accidents cannot be neglected. A hoist system requires inspection and maintenance and must be operated within specified limits. A pristine chain may fail with a load of 14,500 pounds but a severe, undetected nick in the chain can seriously degrade its performance. Therefore, we expect that human factors would contribute most to load-drop accidents using the PT-III hoist during RS mate or demate operations in a silo or RS upload or download operations in the AS\&I building for a MMIII wing. 
This Page Intentionally Left Blank 


\section{Summary and Conclusions}

We assessed the hoist failure rate for the PT-III hoist as one of the ground transportation tasks for the MMIII WSSA. The failures of concern here are those that lead to dropping a RS during hoist operations in a MMIII silo or the AS\&I building. We provided a short description of the PT-III hoist system and summarized our attempts to acquire information on electric hoist system failures from literature searches, personal communications, and observation of PT-II operations. Failure mechanisms that can cause load-drop accidents were discussed. We described a procedure for estimating an upper bound for the chain failure rate from destructive load and fatigue testing of the hoist chain. We also discussed other failure mechanisms.

We make the following conclusions based on our assessment:

- No historical data from industry and the military services for failures of electric chain hoists leading to load drops seem to exist.

- At least seven hoist failure mechanisms that can cause a load-drop accident were identified: chain failure, load block failure, clevis failure, controller faiiure, brake failure, hoist disassembly, and support structure collapse. Data were found to estimate failure rates for the PT-III hoist due to chain failure. No data were found to estimate failure rates due to the other mechanisms.

- On the basis of destructive test data provided by Martin-Marietta Corporation for the PT-III Hoist chain, we determined an upper bound of $4 \times 10^{-14} \mathrm{RS}$ drops per year in silos for a MMIII wing performing $718 \mathrm{RS}$ mate or demate operations in a year and an upper bound of $1 \times 10^{-14} \mathrm{RS}$ drops per year at the AS\&I building for a wing performing 260 RS upload or download operations in a year.

- On the basis of the Duff-Norton Company S-N curve from fatigue test data and the load weights of the PT-III, we do not expect the chain to fail due to fatigue during hoist operations involving an RS, MSG, SRE, or PBCS.

- The hook failure rate published in the OREDA Offshore Reliability Data Handbook that was cited in the LLNL Phase I Study is not applicable to PT-III hoist failure.

- Failure rates for mechanisms other than chain failure could be determined by further destructive testing of the components of the PT-III hoist system, or possibly by quantitative fault-tree analyses using surrogate data. 
- Failure rates for hoist components, the RS handling fixture, and the cable support system that are designed with PT-III safety factors are expected to he no larger than the upper bounds for the chain failure rates that were calculated from destructive test data.

- The PT-III Hoist System is well designed with large safety factors. Therefore, we expect that human factors will contribute more to load-drop accidents than mechanical failures within the hoist system during PT-III hoist operations. Of particular concern is human error in not detecting flaws in the chain. We did not attempt to quantify the effects of human factors since this task was beyond the scope of our study.'

${ }^{1}$ As part of the MMIII WSSA, DNA initiated a human factors analysis. Capt. Bredehoft reported this information at the Model/Test Working Group (MTWG) Meeting on February 11, 1993, in Albuquerque, NM at R\&D Associates. Inspection of the hoist chain and other components was identified as a concern. At a MTWG Meeting at LLNL on July 21, 1993, the probability of detecting a 0.03-inch crack or a dent was reported to be 0.65 . Other concerns include errors in assembling and attaching the RS, MGS, PSRE, or PBCS handling equipment and tool or equipment drops down the launch tube. 


\section{References}

1. Homsy, R. V. R. C. Basinger, and E. H. Moor, ICBM Replacement Warhead Phase I Study Safety Working Group Report (U), CD-92-0127, Lawrence Livermore National Laboratory, Livermore, CA, April 1992.

2. OREDA Offshore Reliability Data Handbook, 1st edition, PennWell Publishing Company, 1984.

3. Perkins, D., Payload Transporter Type III Qualification Test Report Qualification Load and Functional Test, MCR-92-6523, Martin Marietta Corporation, Denver, CO, July 1992.

4. Harris, J. L., Orbiter Processing Facility Service Platform Failure and Redesign, The 22nd Aerospace Mechanisms Symposium, N88-21494, NASA, Langley, VA.

5. Burek, D. M., Encyclopedia of Associations, 27th edition, Vol. 1, Gale Research Inc., Detroit, MI, 1993.

6. Deas, W. A., JL-19-B and JL-19-1B Chain Test, Test Report Number 2247, Duff-Norton Company Engineering Test Laboratory, Charlotte, NC, August 1985.

7. Densson, W., A. Chandler, W. Crowell, and R. Wanner, Nonelectronic Parts Reliability Data 1991, NPRD-91, Reliability Analysis Center, Rome, NY, 1991.

8. West, W. L., Semitrailer Payload Transporter, AM 32A-47D, CI04749AA, PT, Nuclear Safety Analysis Report, MCR-90-3223-02, Martin Marietta Corporation, Denver, CO, July 1992.

9. Lyles, D., Reliability Predictions Report for Payload Transporter, Type III, MCR-90-3230, Martin Marietta Corporation, March 1991.

10. Kahaner, D., C. Moler, and S. Nash, Numerical Methods and Software, Prentice Hall, Englewood Cliffs, NJ, 1989.

11. Miller, I. and J. E. Freund, Probability and Statistics for Engineers, Prentice Hall, Englewood Cliffs, NJ, 1965. 
This Page Intentionally Left Blank 
Distribution:

$\begin{array}{ll}\text { HQ DNA/NOSA } & \text { Lt. Col. W. Andrews } \\ \text { HQ DNA/NOSA } & \text { Capt. B. B. Bredehoft } \\ \text { HQ DNA/NOSA } & \text { LCDR K. M. Stein } \\ \text { MS0100/7613-2 } & \text { Document Processing for DOE/OSTI (10) } \\ \text { MS0490/12331 } & \text { J. A. Cooper } \\ \text { MS0490/12331 } & \text { NSIC File 1N1041 } \\ \text { MS0490/12331 } & \text { S. D. Spray } \\ \text { MS0491/12333 } & \text { P. N. Demmie (6) } \\ \text { MS0491/12333 } & \text { R. E. Smith } \\ \text { MS0492/12324 } & \text { P. E. D'Antonio } \\ \text { MS0492/12332 } & \text { G. A. Sanders } \\ \text { MS0492/12332 } & \text { C. G. Shirley } \\ \text { MS0619/7151 } & \text { Technical Publications } \\ \text { MS0631/12300 } & \text { R. L. Schwoebel } \\ \text { MS0790/9612 } & \text { B. D. Boughton } \\ \text { MS0899/7141 } & \text { Technical Library (5) } \\ \text { MS9018/8523-2 } & \text { Central Technical Files }\end{array}$



(20) 